\title{
Eye fluke-induced cataracts in natural fish populations Is there potential for host manipulation?
}

\author{
Journal Article \\ Author(s): \\ Seppälä, O.; Karvonen, A.; Valtonen, E.T. \\ Publication date: \\ 2011-02 \\ Permanent link: \\ https://doi.org/10.3929/ethz-b-000028156 \\ Rights / license: \\ In Copyright - Non-Commercial Use Permitted \\ Originally published in: \\ Parasitology 138(2), https://doi.org/10.1017/S0031182010001228
}




\title{
Eye fluke-induced cataracts in natural fish populations: is there potential for host manipulation?
}

\author{
O. SEPPÄLÄ ${ }^{1}$, A. KARVONEN ${ }^{2}$ and E. T. VALTONEN ${ }^{3}$ \\ ${ }^{1}$ EAWAG, Swiss Federal Institute of Aquatic Science and Technology, and ETH-Zürich, Institute of Integrative Biology, \\ Überlandstrasse 133, PO Box 611, CH-8600, Dübendorf, Switzerland \\ ${ }^{2}$ Department of Biological and Environmental Science, Centre of Excellence in Evolutionary Research, PO Box 35, \\ FIN-40014, University of Fyväskylä, Finland \\ ${ }^{3}$ Department of Biological and Environmental Science, PO Box 35, FIN-40014, University of Fyväskylä, Finland
}

(Received 12 May 2010; revised 19 Fuly 2010; accepted 19 Fuly 2010; first published online 27 August 2010)

\section{SUMMARY}

\begin{abstract}
Manipulation of host phenotype (e.g. behaviour, appearance) is suggested to be a common strategy to enhance transmission in trophically transmitted parasites. However, in many systems, evidence of manipulation comes exclusively from laboratory studies and its occurrence in natural host populations is poorly understood. Here, we examined the potential for host manipulation by Diplostomum eye flukes indirectly by quantifying the physiological effects of parasites on fish. Earlier laboratory studies have shown that Diplostomum infection predisposes fish to predation by birds (definitive hosts of the parasites) by reducing fish vision through cataract formation. However, occurrence of cataracts and the subsequent potential for host manipulation in natural fish populations has remained poorly explored. We studied the occurrence of eye flukeinduced cataracts from 7 common fish species (Gymnocephalus cernuus, Rutilus rutilus, Leuciscus leuciscus, Alburnus alburnus, Osmerus eperlanus, Coregonus lavaretus and Gasterosteus aculeatus) from the Bothnian Bay in the Baltic Sea. We found that the parasite-induced cataracts were common in fish and they also reached high levels which are likely to predispose fish to predation. However, we observed such cataracts only in species with the highest parasite abundances, which suggests that only certain hosts may be strongly affected by the infection.
\end{abstract}

Key words: Diplostomum, parasite-host interactions, parasite transmission, predation, Trematoda.

\section{INTRODUCTION}

Several parasite species that are transmitted trophically from prey to predators alter the phenotype (e.g. behaviour, appearance) of their intermediate hosts (reviewed by Moore, 2002). These changes can be beneficial for parasites if they make infected hosts easier prey for target hosts (next hosts in the life cycle) and this way increase parasite transmission efficiency (Rothschild, 1962; Holmes and Bethel, 1972). Indeed, parasite-induced modifications in host phenotype have been shown to predispose hosts to predation in several parasite-host interactions (e.g. Bethel and Holmes, 1973, 1977; Moore, 1983; Lafferty and Morris, 1996; Mouritsen and Poulin, 2003; Lagrue et al. 2007; Seppälä et al. 2008a), which is why the ability of parasites to induce such effects is widely considered as adaptive host manipulation. However, in many study systems, host manipulation has been studied only under laboratory conditions (but see e.g. Moore 1983; Mouritsen and Poulin, 2003; Lagrue et al. 2007). Although laboratory

* Corresponding author: EAWAG, Swiss Federal Institute of Aquatic Science and Technology, and ETHZürich, Institute of Integrative Biology, Überlandstrasse 133, PO Box 611, CH-8600, Dübendorf, Switzerland. Tel: + 4144823 5348. Fax: + 414482350 28. E-mail: otto. seppaelae@eawag.ch studies are important when investigating host manipulation experimentally, they can not address the extent of manipulation in natural host populations where it can be affected, for example, by variation in infection dynamics and use of alternative host species. Therefore, more field studies are needed to estimate how common host manipulation is in natural host populations.

In this study, we examined the effect of parasitic eye flukes of the genus Diplostomum (Trematoda) on their natural fish hosts. Diplostomum parasites infect a wide variety of freshwater and brackish water fish species (Valtonen and Gibson, 1997), and their metacercarial stages induce cataract formation in the eye lenses of fish, which reduces their vision (Rushton, 1937, 1938; Karvonen et al. 2004a). In earlier laboratory studies, Diplostomum infection has been shown to alter fish behaviour (Crowden and Broom, 1980; Seppälä et al. 2004, 2008b) and appearance (Seppälä et al. 2005a) so that their vulnerability to avian predators (definitive hosts of the parasites) increases (Seppälä et al. 2004, 2005b). The most likely mechanism leading to these effects is the impaired vision of fish due to parasite-induced cataracts; the susceptibility of fish to predation increases with the coverage of cataracts of the lens area (Seppälä et al. 2005b). Furthermore, cataract formation and subsequent increase in predation 
vulnerability is most intensive after parasites become infective to birds (Seppälä et al. 2005b). Therefore, the ability of these parasites to alter host phenotype through cataract formation is likely to be a parasite adaptation to enhance transmission to bird hosts.

Most of the previous evidence, however, comes from laboratory studies using farmed rainbow trout (Oncorhynchus mykiss) as a model host species, which is why the occurrence of manipulation in natural fish populations is poorly understood. Based on the laboratory evidence, however, the degree of manipulation is linked directly to the coverage of parasiteinduced cataracts (Seppälä et al. 2005b). Thus, potential for manipulation in natural populations could be approached indirectly by using cataract coverage as a proxy for manipulation. In an earlier study, parasite-induced cataracts have been observed in natural populations of walleye (Stizostedion vitreum) and white sucker (Catostomus commersoni) (Marcogliese et al. 2001) suggesting that these species are potentially manipulated by the parasite. However, to our knowledge, such information is lacking for most fish species infected by Diplostomum parasites.

The aim of the present study was to quantify the occurrence of parasite-induced cataracts in fish populations across a natural host community and subsequently assess potential for host manipulation by Diplostomum eye flukes in the wild. It is important to note that the taxonomy of these parasites is not completely resolved (see Gibson, 1996; Galazzo et al. 2002), and fish are often infected with more than one eye fluke species (e.g. Valtonen and Gibson, 1997; Locke et al. 2010). Therefore we refer to Diplostomum spp. in this work. By sampling populations of 7 fish species from the Bothnian Bay in the Baltic Sea we found that the parasite-induced cataracts were common in fish and they also reached levels that are likely to predispose fish to predation (see Seppälä et al. 2005b). However, we observed intensive cataracts only in species with the highest parasite abundances, which suggests that only certain hosts may be strongly affected by the infection.

\section{MATERIALS AND METHODS}

\section{Data collection}

In May 2006, we sampled 7 fish species, ruffe (Gymnocephalus cernuus), roach (Rutilus rutilus), dace (Leuciscus leuciscus), bleak (Alburnus alburnus), smelt (Osmerus eperlanus), whitefish (Coregonus lavaretus) and three-spined stickleback (Gasterosteus aculeatus), 100 individuals of each, from the N.E. Bothnian Bay $\left(65^{\circ} 06^{\prime} \mathrm{N}, 25^{\circ} 19^{\prime} \mathrm{E}\right)$ in the Baltic Sea. Studied species are very common in the area and thus potentially important hosts for the parasites. We collected the samples in spring, before the beginning of parasite transmission from snails (see Karvonen et al. 2004b). We did this to ensure that the fish were not infected with any recently established parasites since metacercariae generally induce cataracts after they have reached infectivity to the avian hosts (see Seppälä et al. 2005b). We caught the fish using fyke nets and brought them to the laboratory immediately after catching for further examination.

We measured the coverage of parasite-induced cataracts from the lenses of each fish with a Kowa Portable Slit Lamp SL-14 microscope (see Wall and Bjerkås, 1999; Karvonen et al. 2004a) using a subjective scale: $0=$ no cataracts, $1=$ cataracts covering less than $25 \%, 2=$ cataracts covering $25-50 \%$, $3=$ cataracts covering $50-75 \%, 4=$ cataracts covering $75-100 \%$, $5=$ cataracts covering $100 \%$ of the lens horizontal area. We did not estimate 'thickness' of the cataracts. Based on our earlier study on predation vulnerability of infected rainbow trout (Oncorhynchus mykiss) (Seppälä et al. 2005b), we considered cataracts covering more than $50 \%$ of the lens area (mean from both eyes) likely to increase the susceptibility of fish to predation. For the purpose of this study, we considered the effect of cataracts to be similar across the fish species. However, we can not completely rule out the possibility for slight differences in cataract development and degree of manipulation between the fish species, as well as between different Diplostomum species possibly occurring in these fish (see Discussion section). Nevertheless, it is important to note that in all studied fish species, development of cataracts in relation to the number of parasites followed the same general pattern. In lowlevel infections, individual parasites were surrounded by their metabolites, which accumulated with the number of parasites leading to gradual loss of opacity of the lens as the metabolites became overlapping. Furthermore, our goal was not to estimate the exact predation rates of fish, or the mechanisms underlying possible variation in cataract coverage among the host species, but instead to use cataract coverage as a proxy of the potential of host manipulation.

Cataracts induced by factors other than parasites (e.g. nutrition, temperature) can also occur in fish (see Bjerkås and Sveier, 2004). However, we considered this unlikely in the present study because the coverage of the cataracts depended on parasite abundance (number of parasites in a fish; Bush et al. 1997) in all studied fish species (Spearman's rank correlation: ruffe: $r=0.833, P<0.001$; roach: $r=0.814$, $P<0.001$; dace: $r=0.739, P<0.001$; bleak: $r=0.743$, $P<0.001$; smelt: $r=0.768, P<0.001$; whitefish: $r=$ $0 \cdot 892, P<0 \cdot 001$; three-spined stickleback: $r=0 \cdot 779$, $P<0 \cdot 001)$, and we did not find any cataracts from the uninfected fish individuals. After determining the coverage of cataracts, we dissected the eye lenses to count the Diplostomum metacercariae in them, and measured the length of each fish $( \pm 1 \mathrm{~mm})$. Since we were only interested in fish suitable in size for avian predation (definitive hosts of the parasites), we did 
Table 1. Number of fish studied $(N)$, body length, prevalence of infection (\%), mean and median abundance of parasites, and estimate of the degree of aggregation of the frequency distribution of parasites $(k)$ in seven wild fish populations studied from the N.E. Bothnian Bay in the Baltic Sea

\begin{tabular}{|c|c|c|c|c|c|c|}
\hline Fish species & $N$ & $\begin{array}{l}\text { Body length }(\mathrm{mm}) \\
\text { Mean } \pm \text { s.E. }\end{array}$ & Prevalence & $\begin{array}{l}\text { Abundance } \\
\text { Mean }\end{array}$ & Median & $k$ \\
\hline G. cernuus & 98 & $106 \pm 1 \cdot 9$ & 100 & $20 \cdot 0$ & $19 \cdot 0$ & $2 \cdot 90$ \\
\hline R. rutilus & 98 & $141 \pm 1 \cdot 3$ & 100 & $30 \cdot 8$ & $23 \cdot 0$ & $1 \cdot 82$ \\
\hline L. leuciscus & 92 & $160 \pm 1 \cdot 3$ & 100 & $79 \cdot 3$ & $65 \cdot 0$ & $3 \cdot 66$ \\
\hline A. alburnus & 99 & $130 \pm 1 \cdot 2$ & 90 & $4 \cdot 4$ & $4 \cdot 0$ & $2 \cdot 20$ \\
\hline O. eperlanus & 98 & $151 \pm 1 \cdot 5$ & 91 & $5 \cdot 6$ & $4 \cdot 0$ & $1 \cdot 47$ \\
\hline C. lavaretus & 86 & $140 \pm 3 \cdot 6$ & 70 & $5 \cdot 6$ & $2 \cdot 5$ & $0 \cdot 51$ \\
\hline G. aculeatus & 99 & $64 \pm 0 \cdot 4$ & 76 & $2 \cdot 1$ & $2 \cdot 0$ & $1 \cdot 65$ \\
\hline
\end{tabular}

not consider fish longer than $200 \mathrm{~mm}$ (see Bugoni and Vooren, 2004; Mauco and Favero, 2004). From a total of 30 fish, we could not determine either cataract coverage or parasite abundance and we excluded them from the data.

\section{Statistical analyses}

We analysed the variation in the coverage of parasiteinduced cataracts between fish species using a Kruskal-Wallis test. We used a non-parametric test because we measured cataract coverage using an ordinal scale ( 6 categories; see above). In the analysis, we used the mid-value from both eyes as a response variable. Furthermore, because frequency distributions of most macroparasites are aggregated in the host populations (i.e. most individuals have low parasite abundances, and only few have very high abundances; see Shaw et al. 1998), we estimated the degree of aggregation in our study populations using maximum-likelihood methods (see Wilson et al. 1996). Since our data showed aggregation in all studied fish populations (Table 1; the distribution converges to Poisson when $k>20$ (Wilson et al. 1996), we analysed the variation in parasite abundance between the fish species using a generalized linear model (GZLM) with negative binomial errors and log-link function. We also analysed the relationship between parasite abundance and cataract coverage among the fish species using a Spearman's rank correlation. In the analysis, we used the medians of parasite abundance and cataract coverage as variables. We conducted all analyses and distribution fitting using the R 2.8.0 statistical package.

\section{RESULTS}

We found parasite-induced cataracts from all studied fish species (Fig. 1), and the cataract coverage reached high levels (i.e. the mid-coverage of both eyes being at least $50 \%$ which potentially predisposes fish to predation (see Seppälä et al. 2005b) in $13 \%$ of the studied fish individuals. However, the coverage of cataracts varied between the fish species
(Kruskal-Wallis test: $\chi_{6}^{2}=379 \cdot 46, P<0 \cdot 001$; Fig. 1), and we observed intensive cataracts ( $>50 \%$ coverage) only in dace $(66 \%$ of individuals), ruffe $(14 \%$ of individuals) and roach (11\% of individuals). Furthermore, the abundance of infection between the fish species was highly variable (GZLM: estimate $=0.20$, s.e. $=0.03, Z=7 \cdot 71, P<0.001)$, mean and median abundances ranging from $2 \cdot 1$ and $2 \cdot 0$ in three-spined stickleback to 79.3 and 65.0 in dace, respectively (Table 1 ). The rank correlation between parasite abundance and cataract coverage (medians) was positive among the fish species (Spearman's rank correlation: $r=0 \cdot 898, P=0 \cdot 006$ ), which suggests that the between-species variation in the coverage of parasite-induced cataracts was at least partly determined by variation in parasite abundance.

\section{DISCUSSION}

Trophically transmitted parasites commonly increase their transmission probability by manipulating their intermediate hosts' phenotype in ways which predispose them to predation (reviewed by Moore, 2002). Diplostomum eye flukes are also known to alter fish behaviour (Crowden and Broom, 1980; Seppälä et al. 2004, 2008b) and appearance (Seppälä et al. 2005a) so that their vulnerability to predation increases (Seppälä et al. 2004, 2005b). The most likely mechanism leading to host manipulation in this system is cataract formation induced by the parasites (Seppälä et al. 2005b). However, the formation of parasite-induced cataracts and host manipulation have been described in detail only under laboratory conditions using farmed rainbow trout as a model host species (Seppälä et al. 2005b). Thus, the occurrence of cataracts and the subsequent potential for host manipulation in natural host populations have remained largely unknown (but see Marcogliese et al. 2001). In this study, we found that the parasiteinduced cataracts are common in natural fish populations, and they can reach levels which potentially predispose fish to predation $(>50 \%$ coverage; see Seppälä et al. 2005b). This suggests that Diplostomum 

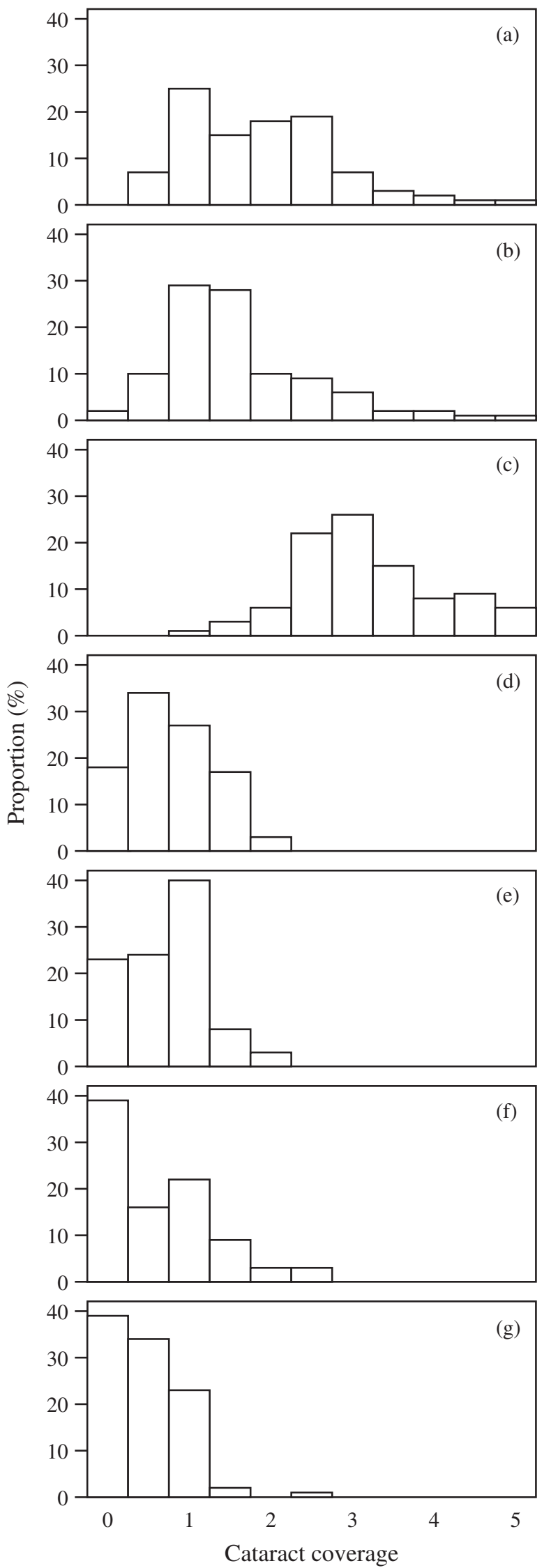

Fig. 1. Frequency distributions (proportions) of parasiteinduced cataracts observed in eye lenses of (a) G. cernuus, (b) R. rutilus, (c) L. leuciscus, (d) A. alburnus, (e) O. eperlanus, (f) C. lavaretus and (g) G. aculeatus studied from N.E. Bothnian Bay in the Baltic Sea. parasites are likely to manipulate their fish hosts in nature.

Although parasite-induced cataracts were common in the studied fish populations, the coverage of cataracts varied greatly between the fish species. We found intensive cataracts $(>50 \%$ coverage) only in dace $(66 \%$ of individuals), ruffe (14\% of individuals) and roach (11\% of individuals), which suggests that only certain species may be strongly affected by the infection. It is important to note, however, that we did not measure the susceptibility of fish to predation directly, but estimated the potential for host manipulation in terms of cataract coverage. Thus, the effect of the infection on actual predation rates can be different if, for instance, the effect of cataracts in different species is not similar. For example, species preferring shallow waters, such as dace and roach, are likely to be exposed to avian predation more frequently than benthic fish such as ruffe. This is because many bird species, such as gulls and terns, are able to catch fish only from the water surface whereas diving birds, such as loons and mergansers, can reach also deeper water layers. Therefore, possible increase in the susceptibility to predation due to cataracts is likely to depend also on host ecology. Furthermore, because we sampled natural fish populations, it is possible that individuals with the highest coverage of cataracts were under-represented in the samples if, in general, they are rapidly removed from the populations by predators (see Seppälä et al. $2005 b)$. This could mean that the species with the lowest observed cataract coverage $(<25 \%$ of the lens area; bleak, smelt, whitefish, three-spined stickleback) were actually the most strongly manipulated. This, however, is unlikely because the intermediate cataract intensities (i.e. $25-50 \%$ coverage), below the proposed 'threshold' of manipulation (50\% coverage; Seppälä et al. 2005b), were mostly missing in those species.

The coverage of cataracts also depended on parasite abundance so that we found intensive cataracts $(>50 \%$ coverage) only from the species with the highest parasite abundances (dace, roach and ruffe). This suggests that the abundance of infection at least partly explains the observed differences in the coverage of parasite-induced cataracts among the fish species (see also Karvonen et al. 2004a). Thus, factors underlying variation in parasite abundance likely contribute also to variation in cataract formation. However, also other factors may be important. For example, as we did not determine the parasite species identity in the studied fish populations, the

The coverage of cataracts was measured using a subjective scale: $0=$ no cataracts, $1=$ cataracts covering less than $25 \%$, $2=$ cataracts covering $25-50 \%, 3=$ cataracts covering $50-75 \%, 4=$ cataracts covering $75-100 \%, 5=$ cataracts covering $100 \%$ of the lens horizontal area. The mid-values of both eyes are shown in the figure. 
fish may have been infected with different eye fluke species (see Locke et al. 2010). This may have brought some additional variation in cataract formation among the fish species. However, Diplostomum species infecting fish eye lenses are ecologically (e.g. life cycle, transmission strategies) very similar. Thus, their ability to induce cataracts can be expected to be under similar selective pressures, and the differences among species are likely to be small. Furthermore, it is possible that fish species differ in their susceptibility to cataract formation, i.e. a certain abundance of infection may induce different coverage of cataracts in different species. This is possible, for example, because the size of the lens varies considerably between fish species (Karvonen and Seppälä, 2008), and the number of parasites required to impair fish vision is likely to increase with lens size. This suggests that the species with the smallest lenses could be most vulnerable to reduction in vision due to the infection. This question, however, could not be addressed using these data and would require controlled experimental infections of uninfected individuals under laboratory conditions. However, techniques for the production and maintenance of several wild fish species under parasite-free laboratory conditions are currently not available.

To conclude, our results show that Diplostomum parasites are able to induce high-level cataracts in the wild populations of their natural fish hosts. This supports the earlier conclusions from laboratory experiments by suggesting that eye flukes are likely to manipulate fish phenotype also under natural conditions. Potential for manipulation, however, may vary among host species because intensive cataracts were observed only in certain fish species. Thus, different host species may not be equally affected by the infection and only some of them may be primarily responsible for maintaining the parasite populations ('required hosts'; sensu Holmes, 1979). Furthermore, such variation could be reflected in parasite population dynamics and even energy flow in natural food webs, which is why manipulation could also have wider implications at the ecosystem level (see Lefèvre et al. 2009). These questions, however, remain to be investigated.

\section{ACKNOWLEDGEMENTS}

We thank R. Halonen, P. Rintamäki and T. Valtonen for help in providing the fish, and anonymous reviewers for their comments on the manuscript. The study was funded by Emil Aaltonen Foundation (O.S.), Kone Foundation (O.S.), and the Academy of Finland (O.S., A.K.).

\section{REFERENCES}

Bethe1, W. M. and Holmes, J. C. (1973). Altered evasive behaviour and responses to light in amphipods harboring acanthocephalan cystacanths. Fournal of Parasitology 59, 945-956.
Bethe1, W. M. and Holmes, J. C. (1977). Increased vulnerability of amphipods to predation owing to altered behaviour induced by larval acanthocephalans. Canadian Fournal of Zoology 55, 110-115.

Bjerkås, E. and Sveier, H. (2004). The influence of nutritional and environmental factors on osmoregulation and cataracts in Atlantic salmon (Salmo salar L). Aquaculture 235, 101-122.

Bugoni, L. and Vooren, C. M. (2004). Feeding ecology of the Common Tern Sterna hirundo in a wintering area in southern Brazil. Ibis 146, 438-453.

Bush, A. O., Lafferty, K. D., Lotz, J. M. and Shostak, A. W. (1997). Parasitology meets ecology on its own terms: Margolis et al. revisited. Fournal of Parasitology 83, 575-583.

Crowden, A. E. and Broom, D. M. (1980). Effects of eyefluke, Diplostomum spathaceum, on the behaviour of dace (Leuciscus leuciscus). Animal Behaviour 28, 287-294.

Galazzo, D. E., Dayanandan, D., Marcogliese, D. J. and McLaughlin, J. D. (2002). Molecular systematics of some North American species of Diplostomum (Digenea) based on rDNAsequence data and comparisons with European congeners. Canadian Fournal of Zoology 80, 2207-2217.

Gibson, D. I. (1996). Trematoda. In Guide to the Parasites of Fishes of Canada, Part IV (ed. Margolis, L. and Kabata, Z.), pp. 1-373. Canadian Special Publication of Fisheries and Aquatic Sciences No. 124. NRC Press, Ottawa, Canada.

Holmes, J. C. (1979). Parasite populations and host community structure. In Host-Parasite Interfaces (ed. Nickol, B. B.), pp. 27-46. Academic Press, London, UK.

Holmes, J. C. and Bethel, W. M. (1972). Modification of intermediate host behaviour by parasites. In Behavioural Aspects of Parasite Transmission (ed. Canning, E. U. and Wright, C. A.), pp. 123-149. Academic Press, London, UK.

Karvonen, A. and Seppälä, O. (2008). Eye fluke infection and lens size reduction in fish: a quantitative analysis. Diseases of Aquatic Organisms 80, 21-26.

Karvonen, A., Seppälä, O. and Valtonen, E. T. (2004a). Eye fluke-induced cataract formation in fish: quantitative analysis using an ophthalmological microscope.

Parasitology 129, 473-478.

Karvonen, A., Seppälä, O. and Valtonen, E. T. (2004b). Parasite resistance and avoidance behaviour in preventing eye fluke infections in fish. Parasitology 129, 159-164.

Lagrue, C., Kaldonski, N., Perrot-Minnot, M. J., Motreuil, S. and Bollache, L. (2007). Modification of hosts' behaviour by a parasite: field evidence for adaptive manipulation. Ecology 88, 2839-2847.

Lafferty, K. D. and Morris, K. (1996). Altered behaviour of parasitized killifish increases susceptibility to predation by bird final hosts. Ecology 77, 1390-1397.

Lefèvre, T., Lebarbenchon, C., Gauthier-Clerc, M., Misse, D., Poulin, R. and Thomas, F. (2009).

The ecological significance of manipulative parasites. Trends in Ecology and Evolution 24, 41-48.

Locke, S. A., McLaughlin, J. D., Dayanandan, S. and Marcogliese, D. J. (2010). Diversity and specificity in Diplostomum spp. metacercariae in freshwater fishes revealed by cytochrome $c$ oxidase I and internal 
transcribed spacer sequences. International Fournal for Parasitology 40, 333-343.

Marcogliese, D. J., Dumont, P., Gendron, A. D., Mailhot, Y., Bergeron, E. and McLaughlin, J. D. (2001). Spatial and temporal variation in abundance of Diplostomum spp. in walleye (Stizostedion vitreum) and white suckers (Catostomus commersoni) from the St. Lawrence River. Canadian Fournal of Zoology 79, 355-369.

Mauco, L. and Favero, M. (2004). Diet of the common tern (Sterna hirundo) during the nonbreeding season in Mar Chiquita Lagoon, Buenos Aires, Argentina. Ornitologia Neotropical 15, 121-131.

Moore, J. (1983). Responses of an avian predator and its isopod prey to an acanthocephalan parasite. Ecology 64, 1000-1015.

Moore, J. (2002). Parasites and the Behaviour of Animals. Oxford University Press, Oxford, UK.

Mouritsen, K. M. and Poulin, R. (2003). Parasiteinduced trophic facilitation exploited by a non-host predator: a manipulator's nightmare. International Fournal for Parasitology 33, 1043-1050.

Rothschild, M. (1962). Changes in behaviour in the intermediate hosts of trematodes. Nature, London 193, 1312-1313.

Rushton, W. (1937). Blindness in freshwater fish. Nature, London 140, 1014.

Rushton, W. (1938). Blindness in freshwater fishes. Nature, London 141, 289.

Shaw, D. J., Grenfell, B. T. and Dobson, A. P. (1998). Patterns of macroparasite aggregation in wildlife host populations. Parasitology 177, 597-610.
Seppälä, O., Karvonen, A. and Valtonen, E. T. (2004). Parasite-induced change in host behaviour and susceptibility to predation in an eye fluke-fish interaction. Animal Behaviour 68, 257-263.

Seppälä, O., Karvonen, A. and Valtonen, E. T. (2005a). Impaired crypsis of fish infected with a trophically transmitted parasite. Animal Behaviour 70, 895-900.

Seppälä, O., Karvonen, A. and Valtonen, E. T. (2005b). Manipulation of fish host by eye flukes in relation to cataract formation and parasite infectivity. Animal Behaviour 70, 889-894.

Seppälä, O., Karvonen, A. and Valtonen, E. T. (2008b). Shoaling behaviour of fish under parasitism and predation risk. Animal Behaviour 75, 145-150.

Seppälä, O., Valtonen, E. T. and Benesh, D. P. (2008a). Host manipulation by parasites in the world of dead-end predators: adaptation to enhance transmission? Proceedings of the Royal Society of London, B 275, 1611-1615.

Valtonen, E. T. and Gibson, D. I. (1997). Aspects of the biology of diplostomid metacercarial (Digenea) populations occuring in fishes in different localities of northern Finland. Annales Zoologici Fennici 34, 47-59.

Wall, T. and Bjerkås, E. (1999). A simplified method of scoring cataracts in fish. Bulletin of the European Association of Fish Pathologists 19, 162-165.

Wilson, K., Grenfell, B. T. and Shaw, D. J. (1996). Analysis of aggregated parasite distribution: a comparison of methods. Functional Ecology 10, 592-601. 